\title{
Current and future antenatal management of isolated congenital diaphragmatic hernia
}

\author{
Francesca Maria Russo a, Paolo De Coppi a, b, c, Karel Allegaert ${ }^{\text {a, d }}{ }^{\text {, Jaan Toelen }}{ }^{\text {a }}$, \\ Lennart van der Veeken a, George Attilakos b', Mary Patrice Eastwood ${ }^{\mathrm{a}, \mathrm{b}}$, \\ Anna Louise David ${ }^{\mathrm{b}}$, Jan Deprest ${ }^{\mathrm{a}, \mathrm{b}}$, * \\ a Academic Department of Development and Regeneration, Clinical Specialties Research Groups, Biomedical Sciences; Clinical Department of Obstetrics and \\ Gynaecology, KU Leuven, Leuven, Belgium \\ ${ }^{\mathrm{b}}$ Institute for Women's Health and Institute of Child Health, University College London, London, UK

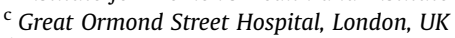 \\ ${ }^{\mathrm{d}}$ Erasmus Medical Centre, Sophia Hospital for Children, Intensive Care Unit for Children, Rotterdam, The Netherlands
}

Keywords:

Congenital diaphragmatic hernia

Prenatal therapy

Pulmonary hypoplasia

Pulmonary hypertension

Sildenafil

\begin{abstract}
A B S T R A C T
Congenital diaphragmatic hernia is surgically correctable, yet the poor lung development determines mortality and morbidity. In isolated cases the outcome may be predicted prenatally by medical imaging. Cases with a poor prognosis could be treated before birth. However, prenatal modulation of lung development remains experimental. Fetoscopic endoluminal tracheal occlusion triggers lung growth and is currently being evaluated in a global clinical trial. Prenatal transplacental sildenafil administration may in due course be a therapeutic approach, reducing the occurrence of persistent pulmonary hypertension, either alone or in combination with fetal surgery.
\end{abstract}

(C) 2017 Elsevier Ltd. All rights reserved.

\section{Introduction}

Congenital diaphragmatic hernia $(\mathrm{CDH})$ occurs in about one in 2500 births; therefore, in the EU-27, about 2100 babies with CDH are born annually. The defect is left-sided in $85 \%$ (LCDH), $13 \%$ are right-sided $(\mathrm{RCDH})$, whereas the remainder are bilateral or have complete agenesis [1,2]. From the embryonic phase, abdominal organs herniate through the defect, interfering with lung growth, resulting in developmental arrest of both airways and vasculature. Hypoplastic lungs have fewer and less mature airway branches and impaired vascular development, including a smaller cross-sectional area of pulmonary vessels, structural vascular remodeling and altered vasoreactivity [3]. At birth, this results in respiratory insufficiency and persistent pulmonary hypertension (PHT), which cannot be solved simply by the surgical repair of the diaphragm. Despite improved and more standardized neonatal management, overall survival of neonates with $\mathrm{CDH}$ remains at around 70\% [4]. PHT is a major cause of neonatal death and morbidity.

\footnotetext{
* Corresponding author. Herestraat 49, 3000 Leuven, Belgium.

E-mail address: jan.deprest@uzleuven.be (J. Deprest).
}

\section{Antenatal assessment}

Prenatal ultrasound identifies two out of three cases of CDH [5], providing the opportunity for in-utero referral to a tertiary care center for expert assessment and perinatal management. Additional genetic and morphologic assessment using ultrasound or magnetic resonance imaging may be used to rule out associated malformations [6]. For isolated cases clinicians can individualize prognosis to counsel parents about prenatal options. A detailed description of potential prognostic indices goes beyond the purpose of this review. Briefly, most of the prediction methods are based on lung size, liver herniation and pulmonary circulation, and more recently stomach position [7-12]. Ultrasound measurement of the lung-to-head ratio (LHR) is most widely used. It involves a standardized two-dimensional ultrasound measurement of the lung contralateral to the defect at the level of the four-chamber view of the heart. The observed LHR is expressed as a proportion of what is expected in a normal fetus of the same gestational age (o/ eLHR), allowing prediction of prognosis independently of gestational age $[7,13]$. The combination of liver herniation and o/eLHR is currently used by prenatal management centers to stratify fetuses with LCDH and RCDH into groups with different increasing pulmonary hypoplasia and corresponding mortality rates (Fig. 1). 
Those with the worst prognosis may be offered intrauterine treatment.

Severity assessment by magnetic resonance imaging (MRI) theoretically has several advantages over ultrasound. Visualization is not limited by maternal habitus, amniotic fluid volume, or fetal position. Furthermore, MRI volumetric measurement of both lungs may better predict postnatal lung function. Volumetry may also accurately quantify liver and stomach herniation $[15,16]$. Though one may claim that MRI better predicts outcome than ultrasound [17], in clinical practice it may be difficult to prove [18].

Lung size and liver herniation also predict neonatal morbidity, such as the duration of assisted ventilation, the need for supplemental oxygen, the need for patch repair and the time it takes to full enteral feeding $[19,20]$. The literature on prediction of PHT is more limited (systematically reviewed in Ref. [21]). Several candidate parameters have been suggested in single case series, including lung size, presence of visceral herniation, and also direct assessment of the pulmonary vasculature, which may provide additional information.

\section{Fetal therapy for CDH today}

The ability to identify a future non-survivor prenatally prompts the quest for a prenatal intervention that can improve outcome. In fetuses with poor prognosis, fetal lung growth can be stimulated by fetoscopic endoluminal tracheal occlusion (FETO) with a balloon [9,22-24]. The concept "plug the lung until it grows" is inspired by clinical observations in fetuses with laryngeal atresia who have a markedly increased lung volume and alveolar number. Airway obstruction prevents egress of pulmonary fluid which experimentally has been shown to prompt lung growth by a mechanism of stretch of lung parenchymal cells [25]. Those experimental findings have been clinically translated into a percutaneous procedure without serious maternal morbidity (Fig. 2).

\subsection{Technique for balloon insertion}

We perform FETO under local anesthesia and sono-endoscopic guidance. First the fetal and placental position are determined for optimal trocar insertion. When necessary, the fetus is externally manipulated to enable a safe and effective access to the mouth. A neuromuscular blocking agent, fentanyl, and atropine are administered to the fetus for immobilization, anesthesia, and prevention of fetal bradycardia, respectively. A disposable, thin-walled flexible cannula, loaded with a pyramidal trocar or using the Seldinger technique, is inserted through the skin and myometrium, avoiding the placenta. Under ultrasound guidance the cannula is targeted to or above the fetal nose tip. Fetoscopic instruments specifically designed for FETO include a slightly bent $3.3 \mathrm{~mm}$ sheath loaded with a fiberoptic endoscope ( $1.3 \mathrm{~mm}$; Karl Storz, Tuttlingen, Germany) and the balloon occlusion system (catheter loaded with a detachable inflatable latex balloon with an integrated one-way valve; Goldbal 2, Balt Extrusion, Montmorency, France). This balloon can accommodate an increasing diameter as the fetal trachea grows during pregnancy. It appears on ultrasound examination as a fluid-filled structure. Through the sheath we also pass a stylet and/or forceps to remove the balloon if wrongly positioned. Irrigation for clearing the operative field and improving visualization can be connected to the side port. Fetoscopic landmarks are the philtrum and upper lip, the tongue and raphe of the palate, uvula, epiglottis, and eventually the vocal cords. The endoscope is advanced into the trachea until identification of the carina, above which the balloon is positioned by inflation and detachment from the catheter. The median duration of FETO is 10 min (range: 3-93), dependent on both the experience of the operator and the position of the fetus [26]. A longer operation time is the main risk factor for membrane rupture.

\subsection{Technique for balloon removal}

Experimental data suggest benefit of temporary tracheal occlusion ("plug-unplug" sequence) by stimulating lung maturation [27,28], which prompted clinicians to attempt timely in-utero reversal as much as possible. Also clinical data suggest that prenatal balloon removal increases neonatal survival [22] and reduces neonatal morbidity [8]. Leaving the tracheal occlusion until delivery may provide additional lung growth and theoretically avoid the risk for preterm delivery from the second fetoscopic intervention of balloon removal [24,29]. Conversely, it may lead to more emergency removals at the time of birth, which are challenging and risky [30].

We therefore schedule elective intrauterine occlusion reversal at 34 weeks in patients with an uneventful postoperative course. We have used ultrasound-guided puncture, fetoscopic removal, tracheoscopic removal on placental circulation, and postnatal puncture. Ultrasound-guided in-utero balloon puncture is done after fetal immobilization and fetal analgesia. The lung fluid, which is at high pressure under the occlusion, pushes the punctured balloon into the pharynx, from where it is either swallowed or falls into the amniotic cavity. Tracheal patency may be confirmed by a change in tracheal diameter and flushing under ultrasound power Doppler examination. Fetoscopic removal is done with similar
A

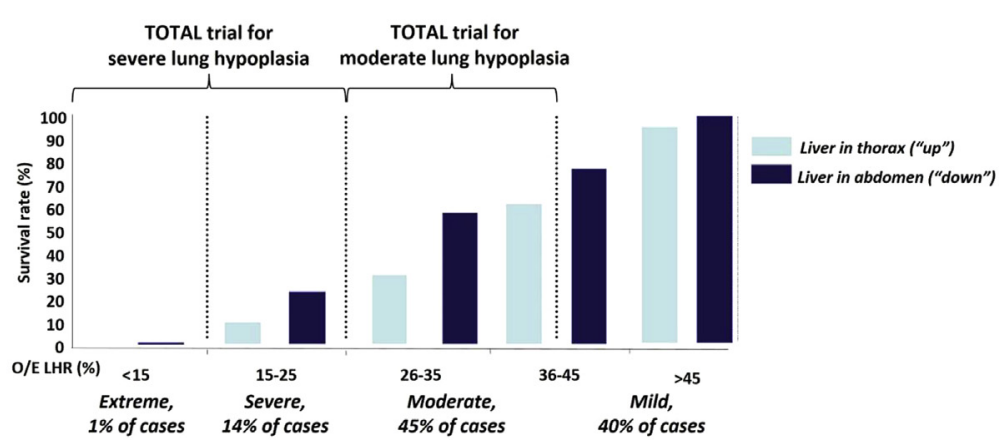

B

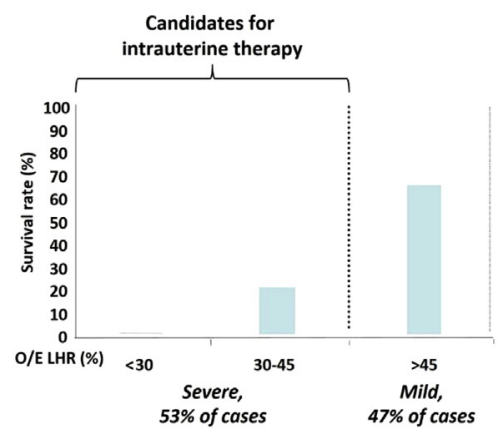

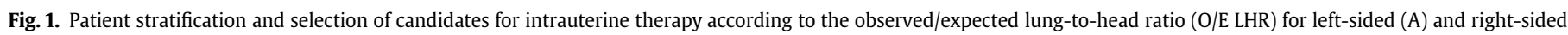
(B) congenital diaphragmatic hernia. Adapted from Jani et al. [13] and DeKoninck et al. [14]. 


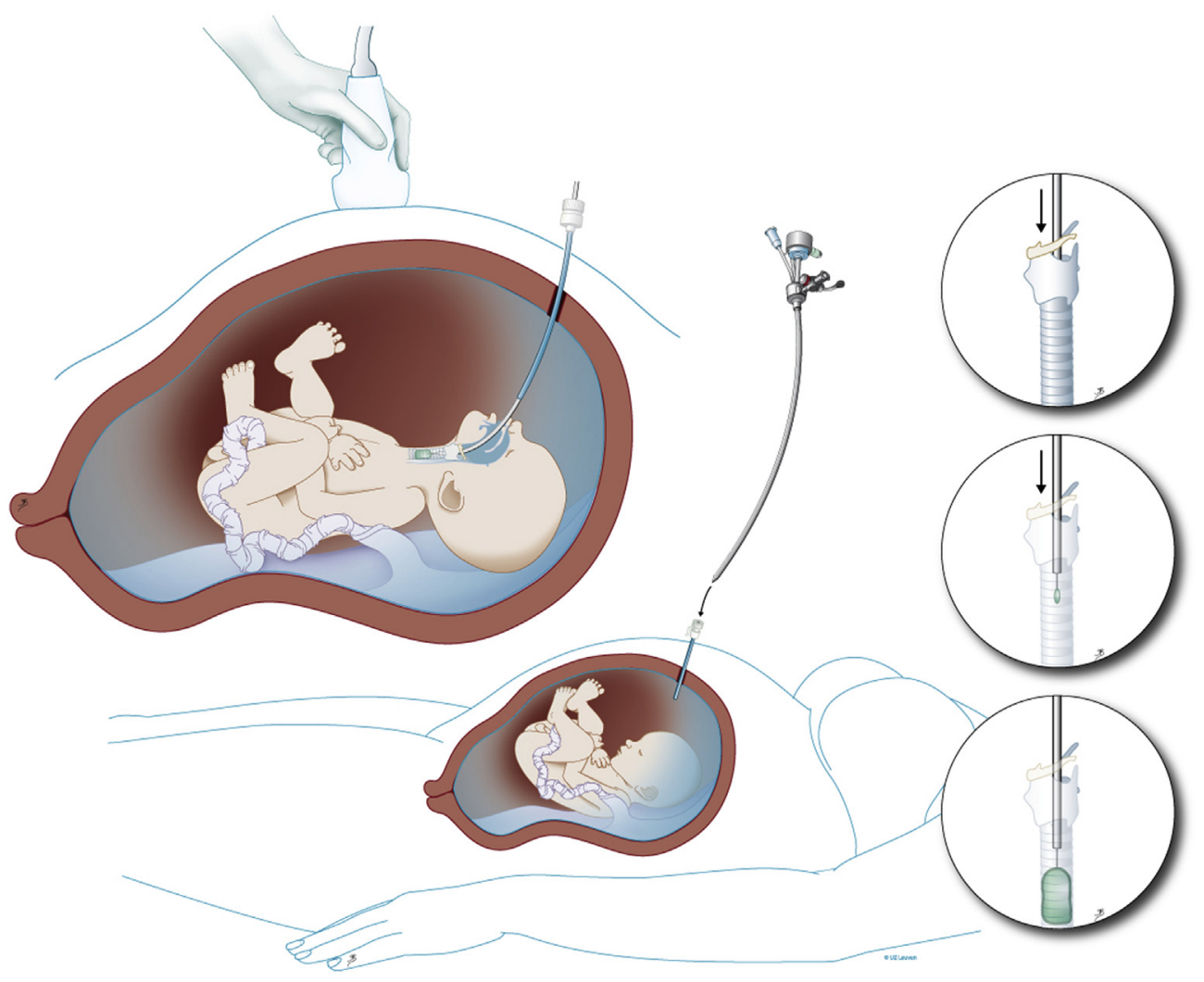

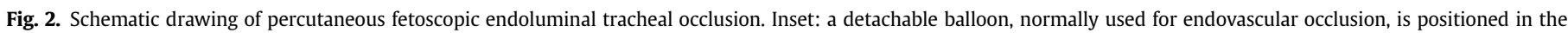
trachea. Reproduced with permission from UZ Leuven, Leuven, Belgium. Drawing: Myrthe Boymans.

instruments as for insertion. Initially we used a forceps (11510C Karl Storz) only, yet fetoscopic puncture with a stylet (11506P Karl Storz) substantially reduced the operation time. The forceps is still used to grasp the tail of the balloon and retrieve it [30].

In $20 \%$ of cases, patients present earlier than planned with threatened preterm delivery, with or without ruptured membranes. Whenever clinically possible, we try to remove the balloon in utero, using the same techniques. This will be delayed as long as possible and may need to be done in an emergency. We have performed in-utero balloon removal in the presence of ruptured membranes, in early labour, or with early signs of chorioamnionitis. If in-utero retrieval does not seem safe or possible, we remove the balloon by laryngo-tracheoscopy during a modified cesarean section under loco-regional anesthesia, with the fetal head and shoulders delivered, while the fetus remains on placental circulation (Fig. 3A) [31]. Post-delivery removal is a last resort, which we do by video laryngo-tracheoscopy, although blind or ultrasound-guided ex-utero puncture have also been reported [32].

We recently reported outcomes on 302 balloon insertions at three FETO centers [30]. Balloon removal was elective in $72 \%$ of cases and as an emergency in $28 \%$. The primary method was by fetoscopy in the majority of cases (67\%), by ultrasound guidance in $21 \%$, by tracheoscopy on placental circulation in $10 \%$, and postnatal tracheoscopy in $1 \%$. In 3\%, a second removal attempt was required. Each surgeon had a different preferred primary technique. There was no difference in the interval to delivery between fetoscopic and ultrasound-guided removal in elective cases. There were nine balloon removals attempted outside the FETO centers. Retrieval was impossible in three cases, leading to iatrogenic neonatal death (Fig. 3B).

\subsection{Outcomes of FETO}

Compared to historical controls of similar severity, FETO increases survival rate from $24 \%$ to $49 \%$ in LCDH with o/eLHR $<25 \%$, and from $17 \%$ to $42 \%$ in RCDH with o/eLHR $<45 \%$ [25,32]. FETO also seems to reduce early neonatal respiratory morbidity $[8,20]$. This potential benefit is now being investigated in two parallel randomized clinical trials (RCT) "Tracheal Occlusion To Accelerate Lung growth" (www.TOTALtrial.eu), in fetuses with LCDH and severe or moderate lung hypoplasia (NCT01240057 and NCT00763737) [33]. Current participating fetal therapy centers are from Europe (Leuven, Belgium; Paris, France; London, UK; Barcelona, Spain; Milan and Rome, Italy; Bonn, Germany); from Toronto, Canada; Brisbane, Australia; and most recently Houston, Texas. The second interim analysis $(n=147)$ of the moderate trial did not identify safety issues. With an increase in recruitment, as additional centers from the USA and Japan will join, it is hoped to finish the moderate lung hypoplasia trial within two to three years. The trial on severe lung hypoplasia cases has reached recruitment for the first interim analysis time-point.

Whatever the outcome of the TOTAL trial, FETO is invasive and has an increased risk for preterm delivery, partly offsetting the beneficial effects of fetal therapy. In our pre-trial experience $(>200$ cases), preterm rupture of membranes <34 weeks occurred in $25 \%$ of patients. Delivery took place at a median of 35 weeks, but $30 \%$ delivered before 34 weeks, requiring urgent balloon retrieval. Gestational age at delivery logically is an important predictor of survival and morbidity in CDH fetuses, with and without fetal therapy [8,34] (Fig. 4). Based on our available data, tracheal occlusion does lead to tracheal widening, without impact on survival or 
A

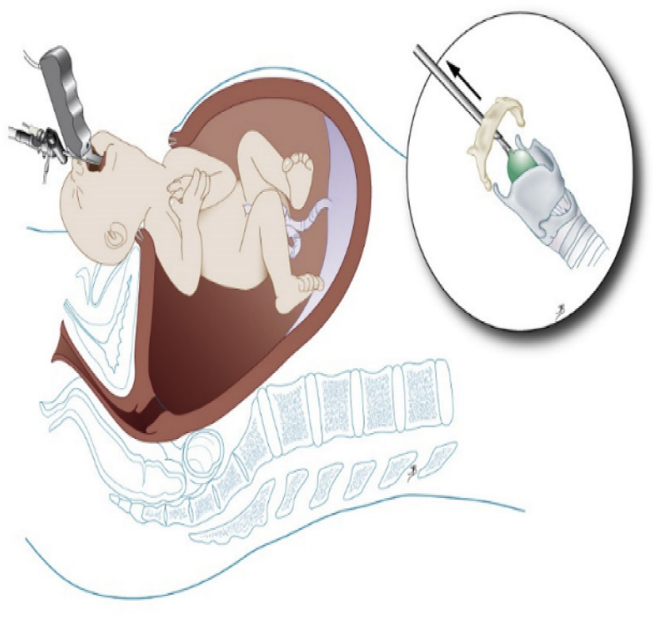

B

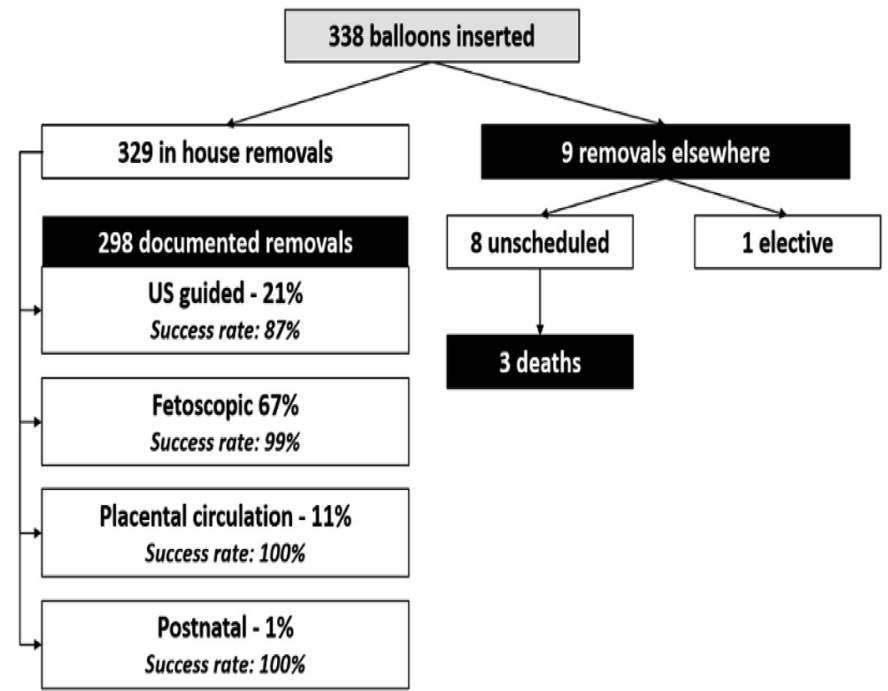

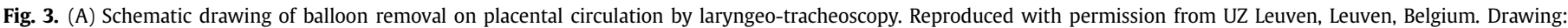

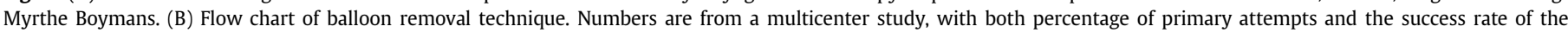
technique. Adapted from Jimenez et al. [30].

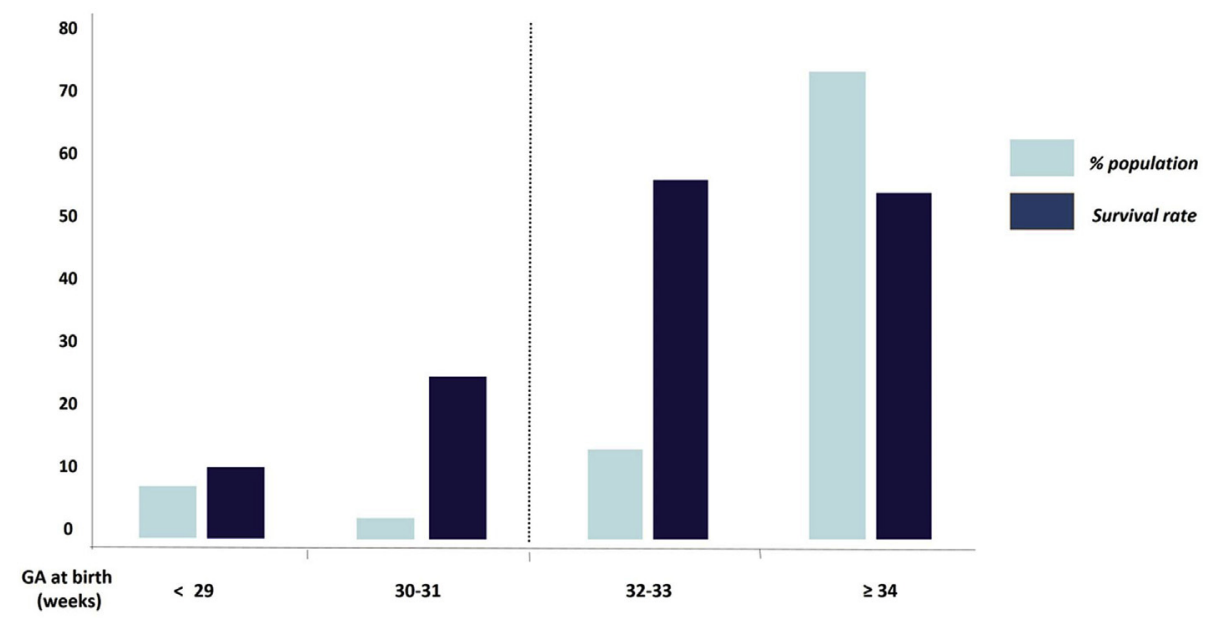

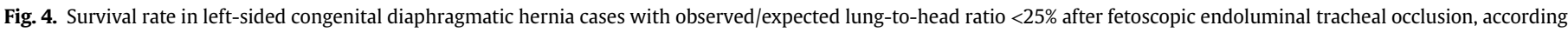
to gestational age (GA) at delivery [34].

the requirement for early respiratory support [35-37].

The logistics and skills for FETO are not always available, therefore FETO is difficult to widely implement. Finally, the maximum post-FETO survival reported in severe cases is $50-60 \%$, which in part is caused by insufficient airway growth and, above all, limited improvement of vascular development. Indeed, whereas FETO increases lung size, it does not seem to solve the problem of PHT. Alternative prenatal strategies are therefore required that also address the problem of PHT. Preferentially these new treatments would be medical rather than surgical, to overcome the risks and limitations of fetal procedures.

\section{Non-surgical experimental antenatal solutions}

We, as well as others, are therefore exploring transplacental pharmacologic modulation of lung development. We have focused on methods also affecting vascular development. Though new ventilation strategies and medical treatments may have improved the outcome of infants with respiratory insufficiency, there is no postnatal therapy with proven efficacy for CDH-related PHT. PHT has become the major cause of mortality and morbidity in $\mathrm{CDH}$ [38]. Infants with $\mathrm{CDH}$, unlike for other causes of neonatal respiratory failure, often present with PHT refractory to inhaled nitric oxide (NO) [39]. The presence and severity of PHT predicts pulmonary morbidity and death $[40,41]$. Beyond PHT in the neonatal period, newly emerging patterns of late (months after birth) and chronic (years after birth) PHT also affect the long-term quality of life in CDH survivors [42]. PHT is also a serious economic burden. Postnatal management costs of a $\mathrm{CDH}$ newborn are higher when PHT is present, mainly due to the increased use of extracorporeal membrane oxygenation [43]. To this, the burden of chronic PHT must be added. Chronic PHT is associated with an increased risk of 
death, cardiac and pulmonary complications and rehospitalization, and requires chronic medical treatment and follow-up [44]. For all these reasons, an effective strategy to treat or prevent PHT would be welcomed. As for airway development, this ideally would already start in utero, in order to prevent the structural changes that lead to PHT after birth.

The best candidate would be a treatment for PHT already proven safe and effective postnatally. Ideally the drug should be effective after maternal intake, and should have no significant adverse effects on the mother or fetus. This strategy would also allow a wider implementation than fetal surgery, including in low-income countries. Such an approach would be the first ever universally affordable therapy for $\mathrm{CDH}$.

\subsection{Sildenafil}

Sildenafil is a selective and potent inhibitor of phosphodiesterase-5 (PDE5), which specifically degrades cyclic guanosine monophosphate (cGMP). It is found in high concentrations in pulmonary arteries and the corpora cavernosa. PDE5 is abundantly expressed during fetal life, where it acts as a key regulator of the perinatal pulmonary circulation [45]. Experimental studies on chronic PHT in newborn animals have demonstrated impaired endothelial release of $\mathrm{NO}$ and increased production of vasoconstrictors [46]. Increased PDE5 activity may contribute to this phenomenon [47].

The mechanism of action of sildenafil on the pulmonary vasculature is depicted in Fig. 5. Apart from having a vasodilatory effect, sildenafil promotes pulmonary angiogenesis and inhibits pulmonary artery remodeling [48]. These properties make sildenafil a potential candidate to prevent the vascular changes leading to PHT in CDH newborns.

Sildenafil is approved by the European Medical Agency and the US Food and Drug Administration for use in PHT in adults [49]. It is also effective and well tolerated in children affected by PHT, as shown in the STARTS RCTs [50,51]. There is a growing interest for the use of sildenafil in the newborn for the treatment of PHT of various etiologies [52], including $\mathrm{CDH}$ [53]. Sildenafil has also already been widely used in pregnant women. There were initial case reports on its chronic use in mothers with PHT, showing maternal improvement without apparent adverse effects on the fetus [54-56]. Sildenafil has also been evaluated in two small case series for the treatment of early onset pre-eclampsia [57] and intrauterine growth restriction (IUGR) [58], and one RCT in pregnancies complicated by idiopathic oligohydramnios [59]. No fetal, neonatal or maternal adverse effects have yet been shown. Finally, there are to our knowledge currently four ongoing Phase III trials with sildenafil treatment during pregnancy, three for severe early onset IUGR [60] and one in normal pregnancies to evaluate safety to reduce intrapartum fetal compromise [61]. All this suggests that sildenafil is a reasonable option to be evaluated in clinical trials with $\mathrm{CDH}$ cases from mid-gestation onwards.

Thébaud was the first to show the benefit of transplacental sildenafil in CDH using the nitrofen-induced model of CDH [62]. Sildenafil was administered subcutaneously to the dams from E11.5 to E20.5 (term $=21 \mathrm{~d}$ ) and was detected in fetal blood. It induced a marked increase in lung cGMP in $\mathrm{CDH}$ fetuses, and a significant attenuation in active PDE5 expression, indicating biological activity in the fetal lung. Sildenafil improved lung structure, increased pulmonary vessel density, reduced right ventricular hypertrophy, and improved postnatal pulmonary artery relaxation. It had no demonstrable adverse effects on the fetal retina and brain, and no adverse maternal effects. Since then, the efficacy of antenatal sildenafil in the nitrofen-CDH rat model has been confirmed [63-66], also when given at a more clinically relevant time [67].

In a recent placebo-controlled trial with transplacental sildenafil given to fetal rabbits with $\mathrm{CDH}$, we confirmed both the safety and efficacy of the drug (Fig. 6) [68]. The rabbit model is clinically more

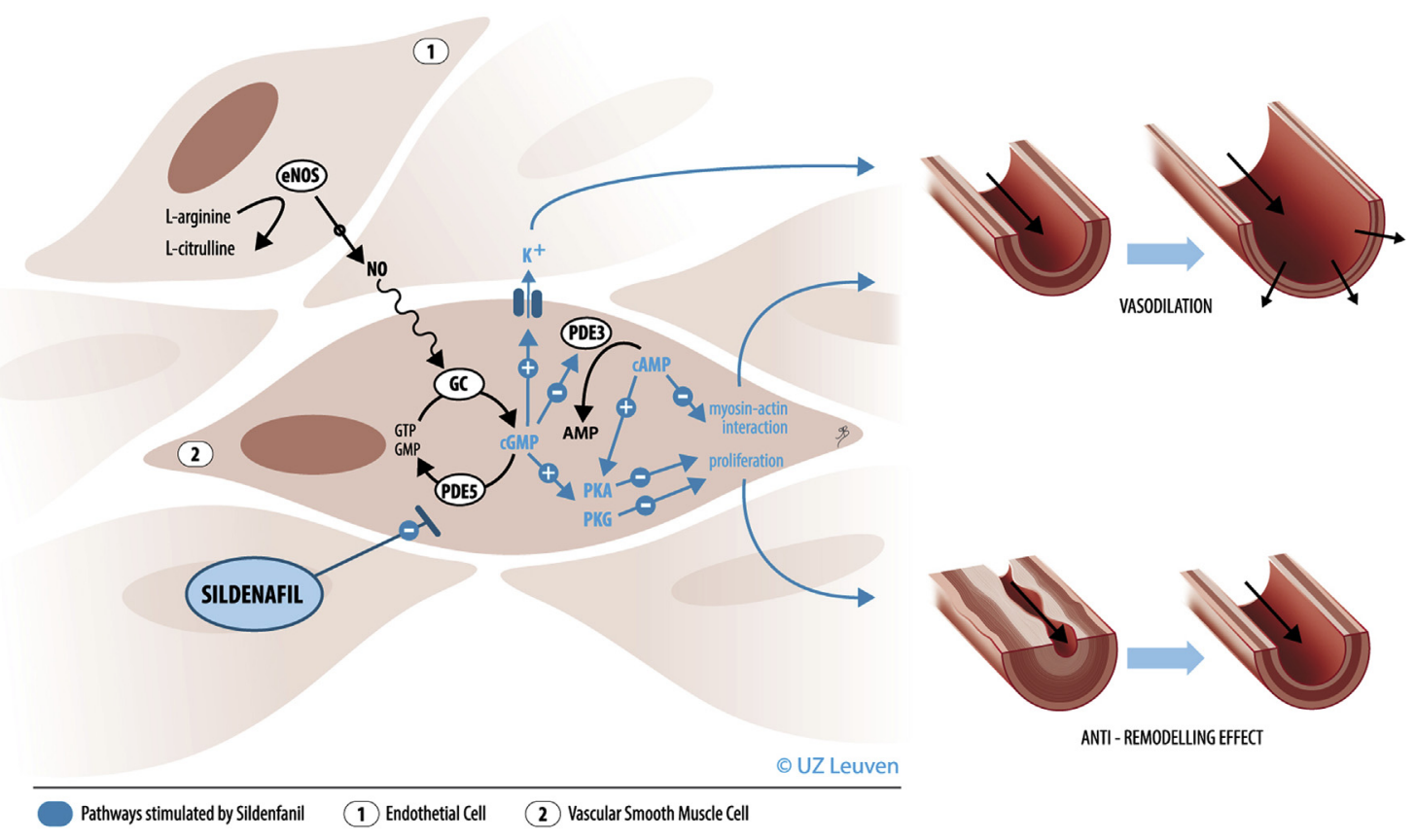

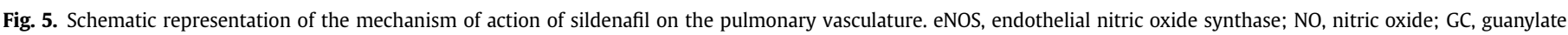

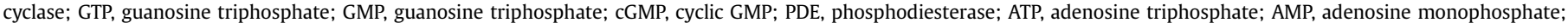

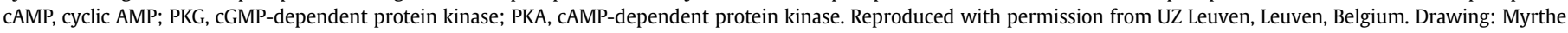
Boymans. 
A

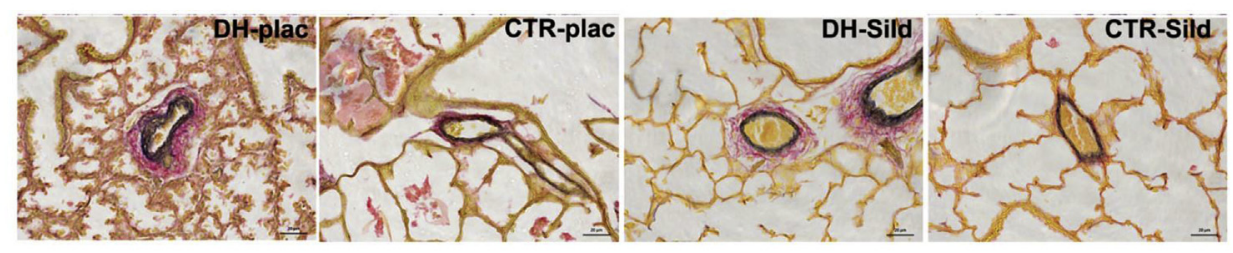

B

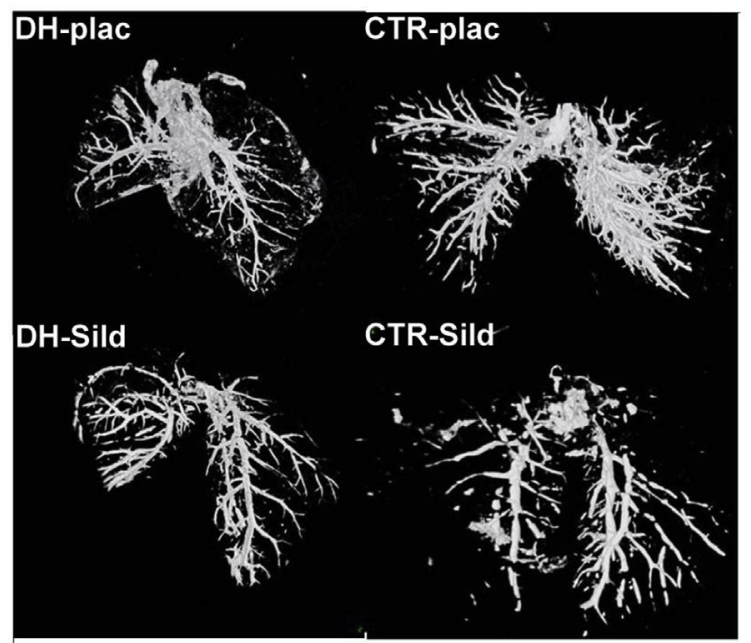

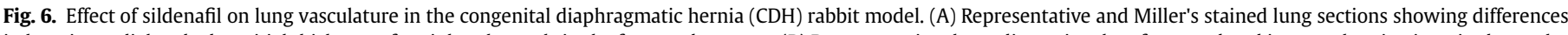

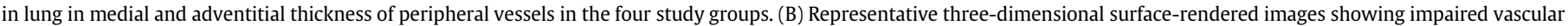
branching in $\mathrm{CDH}$ fetuses, which is restored by exposure to sildenafil. Reproduced, with permission from the publisher, from Russo et al. [68].

relevant than the nitrofen-CDH rodent as it is a larger species. We first performed a dose-finding study demonstrating that subcutaneous administration of $10 \mathrm{mg} / \mathrm{kg} / \mathrm{d}$ sildenafil resulted in therapeutic levels (target $47 \mathrm{ng} / \mathrm{mL}$, proven therapeutic in the STARTS-1 trial for PHT in children [50]) for at least $22 \mathrm{~h} / \mathrm{d}$. There were no differences in maternal weight change, heart rate change, behavior, fetal loss rate, or fetal body weight in animals treated with sildenafil or placebo. Then efficacy was shown in 38 rabbit fetuses with $\mathrm{CDH}$, randomized to either daily placebo or sildenafil from gestational day 24 until term ( $31 \mathrm{~d}$ ). The wall thickness of peripheral pulmonary vessels was increased in placebo-exposed $\mathrm{CDH}$ fetuses as compared to normal controls, yet fell in the normal range when $\mathrm{CDH}$ fetuses were exposed to sildenafil. CDH fetuses also had proportionally more muscularized peripheral vessels than control pups, whereas sildenafil treatment was associated with peripheral muscularization in the normal range. Three-dimensional blood vessel architecture was assessed using micro-computed tomography, showing fewer vessels of the fifth order or higher (thus distal) in placebo-exposed $\mathrm{CDH}$ pups compared to controls. Again, the number of "distal" vessels of sildenafil-exposed CDH fetuses was in the normal range. Small-diameter arteries are the main determinants of pulmonary vascular resistance. An increase in their number will reduce resistance. This, combined with a change in their compliance and thinner and less muscularized walls, should better accommodate postnatal transition and help prevent PHT. We also studied the functional effects of sildenafil, i.e. reduced in-utero pulmonary vascular resistance evidenced at term by microultrasound Doppler studies. Besides the effect on vessels, the drug also improved the morphology of the airways, and improved postnatal lung mechanics as demonstrated by Flexivent ventilation. In summary, sildenafil-induced changes in the vascular compartment were paralleled by changes in airway development. Of interest, sildenafil seemed to have a detrimental effect on vascular branching in non-hypoplastic lungs of normal rabbit fetuses.

We later investigated the effect of combining maternal sildenafil and fetal tracheal occlusion, again in fetal rabbits with CDH [69]. In line with earlier experiments, fetal tracheal occlusion alone restored normal lung size and airway structure, yet did not reverse pathologic changes in peripheral pulmonary vessels. Conversely, sildenafil alone reversed these vascular abnormalities to normal values, yet also partly rescued airway development, again without increasing lung size. $\mathrm{CDH}$ fetuses treated with sildenafil and tracheal occlusion had both a normal lung vascular structure and normal lung parenchyma and size. These results suggest that maternal sildenafil combined with fetal tracheal occlusion have a synergistic effect on vascular and parenchymal lung development.

As a next step to clinical translation, we evaluated transfer of sildenafil through the human placenta, by using an ex-vivo placenta perfusion model [70]. Our preliminary data demonstrate that sildenafil crosses the placenta at a rate that is independent from the initial maternal concentration [71]. The relatively high transfer rate, with a fetal:maternal concentration ratio between 0.93 and 0.97 at steady state, suggests that there is sufficient placental transfer to reach target fetal drug levels at non-toxic maternal doses. All these results have prompted us to apply to the European Medical Agency for orphan designation of this drug for the prenatal prevention of PHT in $\mathrm{CDH}$. 
Practice points

- Patients with an antenatal diagnosis of $\mathrm{CDH}$ should receive individualized counseling on expected outcome.

- In severe to moderate lung hypoplasia cases, prenatal interventions may be considered.

- FETO is the only fetal treatment currently available, yet it is investigational and should be offered within the framework of the TOTAL randomized clinical trial.

- FETO may fail to induce sufficient parenchymal and vascular lung growth and/or may cause prematurity.

Research directions

- Investigating alternative, preferentially non-surgical, antenatal strategies.

- Defining effective interventions to prevent both respiratory insufficiency and PHT.

- Transplacental sildenafil, above all, seems close to clinical application.

\section{Conflicts of interest}

The authors declare no conflict of interest. The KU Leuven has deposited a request for orphan designation for sildenafil to the EMA.

\section{Funding sources}

J.D.P. is a Clinical Researcher of the Flanders Research Foundation (FWO Vlaanderen; 1.8.012.07) and is partly funded by GOSH Children's Charity. P.D.C. is an NIHR Professor and supported by the Catapult Cell Therapy, the GOSH Children's Charity, and GOSH NIHR Biomedical Research Centre's funding scheme. All research at Great Ormond Street Hospital NHS Foundation Trust and UCL Great Ormond Street Institute of Child Health is made possible by the NIHR Great Ormond Street Hospital Biomedical Research Centre. The views expressed are those of the author(s) and not necessarily those of the NHS, the NIHR or the Department of Health. Additionally, P.D.C. and J.D.P. have been jointly funded by GOSHCC, Sparks, and CDHUK. M.P.E. and L.v.V. are supported by the Erasmus + Programme of the European Commission (2013-0040). A.L.D. is supported by the UCL/UCLH NIHR Biomedical Research Centre (BRC award IS-BRC-1215-20012). Our research is in part supported by an Innovative Engineering for Health award by the Wellcome Trust (WT101957), the Engineering and Physical Sciences Research Council (NS/A000027/1), and the Fetal Health Foundation (USA) (ZKD2426, O6510).

\section{Acknowledgments}

We thank our co-workers R. Devlieger, L. De Catte, L. Lewi (UZ Leuven), and R. Wimalasundera (UCLH) for their help in the clinical program. TOTAL co-investigators are thanked for their endurance in this difficult clinical trial, which has already included more than 180 patients.

\section{References}

[1] Butler N, Claireaux AE. Congenital diaphragmatic hernia as a cause of perinatal mortality. Lancet 1962;1(7231):659-63.

[2] Langham Jr MR, Kays DW, Ledbetter DJ, Frentzen B, Sanford LL, Richards DS Congenital diaphragmatic hernia. Epidemiology and outcome. Clin Perinatol 1996;23:671-88.

[3] de Buys Roessingh AS, de Lagausie P, Mercier JC, Aigrain Y, Dinh-Xuan AT Ventilation-induced pulmonary vasodilatation in lambs with congenital diaphragmatic hernia is modulated by nitric oxide. Exp Lung Res 2008;34
$355-71$.

[4] van den Hout L, Schaible T, Cohen-Overbeek TE, Hop W, Siemer J, van de Ven K, et al. Actual outcome in infants with congenital diaphragmatic hernia: the role of a standardized postnatal treatment protocol. Fetal Diagn Ther 2011;29:55-63.

[5] Gallot D, Boda C, Ughetto S, Perthus I, Robert-Gnansia E, Francannet C, et al. Prenatal detection and outcome of congenital diaphragmatic hernia: a French registry-based study. Ultrasound Obstet Gynecol 2007;29:276-83.

[6] Mayer S, Klaritsch P, Petersen S, Done E, Sandaite I, Till H, et al. The correlation between lung volume and liver herniation measurements by fetal MRI in isolated congenital diaphragmatic hernia: a systematic review and metaanalysis of observational studies. Prenat Diagn 2011;31:1086-96.

[7] Jani JC, Benachi A, Nicolaides KH, Allegaert K, Gratacós E, Mazkereth R, et al. Prenatal prediction of neonatal morbidity in survivors with congenital diaphragmatic hernia: a multicenter study. Ultrasound Obstet Gynecol 2009;33: 64-9.

[8] Doné E, Gratacos E, Nicolaides KH, Allegaert K, Valencia C, Castanon M, et al. Predictors of neonatal morbidity in fetuses with severe isolated congenital diaphragmatic hernia undergoing fetoscopic tracheal occlusion. Ultrasound Obstet Gynecol 2013:42:77-83.

[9] Claus F, Sandaite I, DeKoninck P, Moreno O, Cruz Martinez R, Van Mieghem T, et al. Prenatal anatomical imaging in fetuses with congenital diaphragmatic hernia. Fetal Diagn Ther 2011;29:88-100.

[10] Metkus AP, Filly RA, Stringer MD, Harrison MR, Adzick NS. Sonographic predictors of survival in fetal diaphragmatic hernia. J Pediatr Surg 1996;31: 148-51. discussion 151-2.

[11] Doné E, Allegaert K, Lewi P, Jani J, Gucciardo L, Van Mieghem T, et al. Maternal hyperoxygenation test in fetuses undergoing FETO for severe isolated congenital diaphragmatic hernia. Ultrasound Obstet Gynecol 2011;37: 264-71.

[12] Kitano Y, Okuyama H, Saito M, Usui N, Morikawa N, Masumoto K, et al. Reevaluation of stomach position as a simple prognostic factor in fetal left congenital diaphragmatic hernia: a multicenter survey in Japan. Ultrasound Obstet Gynecol 2011:37:277-82.

[13] Jani J, Nicolaides KH, Keller RL, Benachi A, Peralta CF, Favre R, et al. Observed to expected lung area to head circumference ratio in the prediction of survival in fetuses with isolated diaphragmatic hernia. Ultrasound Obstet Gynecol 2007;30:67-71.

[14] Nawapun K, Eastwood M, Sandaite I, DeKoninck P, Claus F, Richter J, et al. Correlation of observed-to-expected total fetal lung volume with in trathoracic organ herniation on magnetic resonance imaging in fetuses with isolated left-sided congenital diaphragmatic hernia. Ultrasound Obstet Gynecol 2015;46:162-7.

[15] Cannie MM, Cordier AG, De Laveaucoupet J, Franchi-Abella S, Cagneaux M, Prodhomme O, et al. Liver-to-thoracic volume ratio: use at MR imaging to predict postnatal survival in fetuses with isolated congenital diaphragmatic hernia with or without prenatal tracheal occlusion. Eur Radiol 2013;23: 1299-305.

[16] Bebbington M, Victoria T, Danzer E, Moldenhauer J, Khalek N, Johnson M, et al. Comparison of ultrasound and magnetic resonance imaging parameters in predicting survival in isolated left-sided congenital diaphragmatic hernia. Ultrasound Obstet Gynecol 2014:43:670-4.

[17] Schaible T, Büsing KA, Felix JF, Hop WC, Zahn K, Wessel L, et al. Prediction of chronic lung disease, survival and need for ECMO therapy in infants with congenital diaphragmatic hernia: additional value of fetal MRI measurements? Eur J Radiol 2012;81:1076-82.

[18] Jani JC, Benachi A, Nicolaides KH, Allegaert K, Gratacos E, Mazkereth R, et al. Prenatal prediction of neonatal morbidity in survivors with congenital diaphragmatic hernia: a multicenter study. Ultrasound Obstet Gynecol 2009;33: 64-9.

[19] Doné E, Debeer A, Gucciardo L, Van Mieghem T, Lewi P, Devlieger R, et al. Prediction of neonatal respiratory function and pulmonary hypertension in fetuses with isolated congenital diaphragmatic hernia in the fetal endoscopic tracleal occlusion era: a single-center study. Fetal Diagn Ther 2015;37:24-32.

[20] Russo FM, Eastwood MP, Keijzer R, Al-Maary J, Toelen J, Van Mieghem T, et al. Lung size and liver herniation predict the need for extracorporeal membrane oxygenation but not pulmonary hypertension in isolated congenital diaphragmatic hernia: a systematic review and meta-analysis. Ultrasound Obstet Gynecol 2017:49:704-13.

[21] Deprest J, Nicolaides K, Doné E, Lewi P, Barki G, Largen E, et al. Technical aspects of fetal endoscopic tracheal occlusion for congenital diaphragmatic hernia. J Pediatr Surg 2011;46:22-32.

[22] Peralta CF, Sbragia L, Bennini JR, de Fatima Assuncao Braga A, Sampaio Rousselet M, Machado Rosa IR, et al. Fetoscopic endotracheal occlusion for severe isolated diaphragmatic hernia: initial experience from a single clinic in Brazil. Fetal Diagn Ther 2011:29:71-7.

[23] Harrison MR, Keller RL, Hawgood SB, Kitterman JA, Sandberg PL, Farmer DL, et al. A randomized trial of fetal endoscopic tracheal occlusion for severe fetal congenital diaphragmatic hernia. N Engl J Med 2003;349:1916-24.

[24] Khan PA, Cloutier M, Piedboeuf B. Tracheal occlusion: a review of obstructing fetal lungs to make them grow and mature. Am J Med Genet 2007;145C: 125-38.

[25] Jani JC, Nicolaides KH, Gratacós E, Valencia CM, Done E, Martinez JM, et al. Severe diaphragmatic hernia treated by fetal endoscopic tracheal occlusion. Ultrasound Obstet Gynecol 2009;34:304-10. 
[26] Flageole H, Evrard VA, Piedboeuf B, Laberge JM, Lerut TE, Deprest JA. The plug-unplug sequence: an important step to achieve type II pneumocyte maturation in the fetal lamb model. J Pediatr Surg 1998;33:299-303.

[27] Nelson SM, Hajivassiliou CA, Haddock G, Cameron AD, Robertson L, Olver RE, et al. Rescue of the hypoplastic lung by prenatal cyclical strain. Am J Respir Crit Care Med 2005:171:1395-402.

[28] Ruano R, Yoshisaki CT, da Silva MM, Ceccon ME, Grasi MS, Tannuri U, et al. A randomized controlled trial of fetal endoscopic tracheal occlusion versus postnatal management of severe isolated congenital diaphragmatic hernia. Ultrasound Obstet Gynecol 2012;39:20-7.

[29] Jiménez JA, Eixarch E, DeKoninck P, Bennini JR, Devlieger R, Peralta CF, et al. Balloon removal after fetoscopic endoluminal tracheal occlusion for congenital diaphragmatic hernia. Am J Obstet Gynecol 2017 Mar 3;217:78.e1-78.e11 [Epub ahead of print].

[30] Deprest J, Brady P, Nicolaides K, Benachi A, Berg C, Vermeesch J, et al. Prenatal management of the fetus with isolated congenital diaphragmatic hernia in the era of the TOTAL trial. Semin Fetal Neonatal Med 2014;19:338-48.

[31] Deprest J, Gratacós E, Nicolaides KH. FETO Task Group. Fetoscopic tracheal occlusion (FETO) for severe congenital diaphragmatic hernia: evolution of a technique and preliminary results. Ultrasound Obstet Gynecol 2004;24: 121-6.

[32] DeKoninck P, Gomez O, Sandaite I. Right-sided congenital diaphragmatic hernia in a decade of fetal surgery. Br J Obstet Gynaecol 2015 Jun;127(7): 940-6 [Epub 2014 Sep 17].

[33] Deprest JA, Hyett JA, Flake AW, Nicolaides K, Gratacós E. Current controversies in prenatal diagnosis 4: should fetal surgery be done in all cases of severe diaphragmatic hernia? Prenat Diagn 2009;29:15-9.

[34] Jani J, Gratacós E, Greenough A, Piero JL, Benachi A, Harrison M, et al. Percutaneous fetal endoscopic tracheal occlusion (FETO) for severe left-sided congenital diaphragmatic hernia. Clin Obstet Gynecol 2005;48:910-22. 35.

[35] Breysem L, Debeer A, Claus F, Proesmans M, De Keyzer F, Lewi P, et al. Crosssectional study of tracheomegaly in children after fetal tracheal occlusion for severe congenital diaphragmatic hernia. Radiology 2010;257:226-32.

[36] Fayoux P, Hosana G, Devisme L, Deprest J, Jani J, Vaast P, et al. Neonatal tracheal changes following in utero fetoscopic balloon tracheal occlusion in severe congenital diaphragmatic hernia. J Pediatr Surg 2010;45:687-92.

[37] Zani A, Sellars M, Allen P, Tyraskis A, Nicolaides K, Greenough A, et al. Tracheomegaly in infants with severe congenital diaphragmatic hernia treated with fetal endoluminal tracheal occlusion. J Pediatr 2014;164:1311-5.

[38] Kotecha S, Barbato A, Bush A, Claus F, Davenport M, Delacourt C, et al. Congenital diaphragmatic hernia. Eur Respir J 2012;39:820-9.

[39] Bagolan P, Morini F. Long-term follow up of infants with congenital diaphragmatic hernia. Semin Pediatr Surg 2007;16:134-44.

[40] Lusk LA, Wai KC, Moon-Grady AJ, Steurer MA, Keller RL. Persistence of pulmonary hypertension by echocardiography predicts short-term outcomes in congenital diaphragmatic hernia. J Pediatr 2015;166:251-6. e1.

[41] Vanamo K, Rintala R, Sovijärvi A, Jaaskelainen J, Turpeinen M, Lindahl H, et al. Long-term pulmonary sequelae in survivors of congenital diaphragmatic defects. J Pediatr Surg 1996;31:1096-9. discussion 1099-1100.

[42] Behrsin J, Cheung M, Patel N. Sildenafil weaning after discharge in infants with congenital diaphragmatic hernia. Pediatr Cardiol 2013;34:1844-7.

[43] Raval MV, Wang X, Reynolds M, Fischer AC. Costs of congenital diaphragmatic hernia repair in the United States - extracorporeal membrane oxygenation foots the bill. J Pediatr Surg 2011;46:617-24.

[44] Sikirica M, Iorga SR, Bancroft T, Potash J. The economic burden of pulmonary arterial hypertension (PAH) in the US on payers and patients. BMC Health Serv Res 2014;14:676.

[45] Vijfhuize S, Schaible T, Kraemer U, Cohen-Overbeek TE, Tibboel D, Reiss I. Management of pulmonary hypertension in neonates with congenital diaphragmatic hernia. Eur J Pediatr Surg 2012;22:374-83.

[46] Villamor E, Le Cras TD, Horan MP, Halbower AC, Tuder RM, Abman SH. Chronic intrauterine pulmonary hypertension impairs endothelial nitric oxide synthase in the ovine fetus. Am J Physiol 1997;272(5 Pt 1):L1013-20.

[47] Hanson KA, Ziegler JW, Rybalkin SD, Miller JW, Abman SH, Clarke WR. Chronic pulmonary hypertension increases fetal lung cGMP phosphodiesterase activity. Am J Physiol 1998;275(5 Pt 1):L931-41.

[48] Barnett CF, Machado RF. Sildenafil in the treatment of pulmonary hypertension. Vasc Health Risk Manag 2006;2:411-22.

[49] Wharton J, Strange JW, Møller GM, Growcott EJ, Ren X, Franklyn AP, et al. Antiproliferative effects of phosphodiesterase type 5 inhibition in human pulmonary artery cells. Am J Respir Crit Care Med 2005;172:105-13.

[50] Barst RJ, Ivy DD, Gaitan G, Szatmari A, Rudzinski A, Garcia AE, et al.
A randomized, double-blind, placebo-controlled, dose-ranging study of ora sildenafil citrate in treatment-naive children with pulmonary arterial hypertension. Circulation 2012;125:324-34.

[51] Barst RJ, Beghetti M, Pulido T, Layton G, Konourina I, Zhang M, et al. STARTS-2: long-term survival with oral sildenafil monotherapy in treatment-naive pediatric pulmonary arterial hypertension. Circulation 2014;129:1914-23.

[52] Steinhorn RH, Kinsella JP, Pierce C, Butrous G, Dilleen M, Oakes M, et al Intravenous sildenafil in the treatment of neonates with persistent pulmonary hypertension. J Pediatr 2009;155:841-7. e1.

[53] Sanchez Luna M, Franco ML, Bernardo B. Therapeutic strategies in pulmonary hypertension of the newborn: where are we now? Curr Med Chem 2012;19: 4640-53.

[54] Lacassie HJ, Germain AM, Valdés G, Fernández MS, Allamand F, López H. Management of Eisenmenger syndrome in pregnancy with sildenafil and $1-$ arginine. Obstet Gynecol 2004;103(5 Pt 2):1118-20.

55] Molelekwa V, Akhter P, McKenna P, Bowen M, Walsh K. Eisenmenger's syndrome in a 27 week pregnancy - management with bosentan and sildenafil. Ir Med J 2005;98:87-8.

[56] Streit M, Speich R, Fischler M, Ulrich S. Successful pregnancy in pulmonary arterial hypertension associated with systemic lupus erythematosus: a case report. J Med Case Rep 2009;3:7255.

[57] Samangaya RA, Mires G, Shennan A, Skillern L, Howe D, McLeod A, et al. A randomised, double-blinded, placebo-controlled study of the phosphodiesterase type 5 inhibitor sildenafil for the treatment of preeclampsia. Hypertens Pregn 2009;28:369-82.

[58] von Dadelszen P, Dwinnell S, Magee LA, Carleton BC, Gruslin A, Lee B, et al. Sildenafil citrate therapy for severe early-onset intrauterine growth restriction. Br J Oobstet Gynaecol 2011;118:624-8.

[59] Maher MA, Sayyed TM, Elkhouly N. Sildenafil citrate therapy for oligohydramnios: a randomized controlled trial. Obstet Gynecol 2017:129:615-20.

[60] Ganzevoort W, Alfirevic Z, von Dadelszen P, Kenny L, Papageorghiou A, van Wassenaer-Leemhuis A, et al. STRIDER: sildenafil Therapy in Dismal prognosis Early-onset intrauterine growth restriction - a protocol for a systematic review with individual participant data and aggregate data meta-analysis and trial sequential analysis. Syst Rev 2014;3:23.

[61] Dunn L, Flenady V, Kumar S. Reducing the risk of fetal distress with sildenafi study (RIDSTRESS): a double-blind randomised control trial. J Transl Med 2016;14:15

[62] Luong C, Rey-Perra J, Vadivel A, Gilmour G, Sauve Y, Koonen D, et al. Antenata sildenafil treatment attenuates pulmonary hypertension in experimenta congenital diaphragmatic hernia. Circulation 2011;123:2120-31.

[63] Yamamoto Y, Thebaud B, Vadivel A, Eaton F, Jain V, Hornberger LK. Dopple parameters of fetal lung hypoplasia and impact of sildenafil. Am J Obstet Gynecol 2014;211:263. e1-8.

[64] Kattan J, Céspedes C, González A, Vio CP. Sildenafil stimulates and dexamethasone inhibits pulmonary vascular development in congenital diaphragmatic hernia rat lungs. Neonatology 2014;106:74-80.

[65] Lemus-Varela Mde L, Soliz A, Gómez-Meda BC, Zamora-Perez AL OrnelasAguirre JM, Melnikov V, et al. Antenatal use of bosentan and/or sildenafi attenuates pulmonary features in rats with congenital diaphragmatic hernia. World J Pediatr 2014;10:354-9.

[66] Burgos CM, Pearson EG, Davey M, Riley J, Jia H, Laje P, et al. Improved pulmonary function in the nitrofen model of congenital diaphragmatic hernia following prenatal maternal dexamethasone and/or sildenafil. Pediatr Res 2016;80:577-85.

[67] Mous DS, Kool HM, Buscop-van Kempen MJ, Koning AH, Dzyubachyk O, Wijnen RM, et al. Clinically relevant timing of antenatal sildenafil treatmen reduces pulmonary vascular remodeling in congenital diaphragmatic hernia. Am J Physiol Lung Cell Mol Physiol 2016;311:L734-42.

[68] Russo FM, Toelen J, Eastwood MP, Jimenez J, Miyague AH, Vande Velde G, et al Transplacental sildenafil rescues lung abnormalities in the rabbit model of diaphragmatic hernia. Thorax 2016:71:517-25.

[69] Russo FM, Monteiro Carvalho Mori Da Cunha MG, Jimenez J, Eastwood MP, Lesage F, Van Mieghem T, et al. Synergic effect of maternal sildenafil and fetal tracheal occlusion improving pulmonary development in the rabbit model for congenital diaphragmatic hernia. Am J Obstet Gynecol 2017:216:S62.

[70] Hutson JR, Garcia-Bournissen F, Davis A, Koren G. The human placental perfusion model: a systematic review and development of a model to predict in vivo transfer of therapeutic drugs. Clin Pharmacol Ther 2011:90:67-76.

[71] Russo FM, Conings S, Annaert P, et al. Placenta transfer of sildenafil citrate in the ex-vivo human cotyledon perfusion model. Am J Obstet Gynecol 2017;216(1):S280. 